\title{
EVALUATION OF THE PERFORMANCE OF A CASTOR-OIL BASED FORMULATION IN LIMITING PESTICIDE RESIDUES IN STRAWBERRY CROPS
}

\author{
Mário Sérgio Galhiane, Sandra Regina Rissato* e Lucídio de Sousa Santos \\ Departamento de Química, Universidade Estadual Paulista, Av. Eng. Luiz E. C. Coube, 14-01, 17033-360 Bauru - SP, Brasil \\ Gilberto Orivaldo Chierice \\ Instituto de Química de São Carlos, Universidade de São Paulo, CP 780, 13560-970 São Carlos - SP, Brasil \\ Marcos Vinícius de Almeida \\ Departamento de Física - Biotecnologia, Universidade Federal de São Carlos, Rod. Washington Luiz, 235, 13565-905 São Carlos \\ - SP, Brasil \\ Terezinha Fumis, Inês Chechim e Aloísio Costa Sampaio \\ Departamento de Biologia, Universidade Estadual Paulista, Av. Eng. Luiz E. C. Coube, 14-01, 17033-360 Bauru - SP, Brasil
}

Recebido em 11/5/11; aceito em 4/8/11; publicado na web em 26/9/11

\begin{abstract}
A study was made to evaluate the effect of a castor oil-based detergent on strawberry crops treated with different classes of pesticides, namely deltamethrin, folpet, tebuconazole, abamectin and mancozeb, in a controlled environment. Experimental crops of greenhouse strawberries were cultivated in five different ways with control groups using pesticides and castor oil-based detergent. The results showed that the group 2, which was treated with castor oil-based detergent, presented the lowest amount of pesticide residues and the highest quality of fruit produced.
\end{abstract}

Keywords: pesticide residue; Ricinus communis; castor oil plant.

\section{INTRODUCTION}

The use of pesticides in agriculture and the resulting contamination of food crops have long been a source of public health concerns. ${ }^{1}$ The use of pesticides is still the main strategy employed in the control and prevention of agricultural pests, aiming at greater productivity allied to lower costs. In the $20^{\text {th }}$ century, the production of pesticides soared as a result of technological and industrial development after World War II. A significant portion of Brazil's economy is based on agriculture, and Brazil ranks in fourth place in the global pesticides market. Although pesticides are potentially toxic to humans, persisting in food crops, water and the environment, they are still widely used and therefore of major economic importance. ${ }^{2}$

To ensure the safe use of pesticides, each country's specific legislation and regulatory agencies standardize their application, e.g., their dosage, forms of application, number of repetitions, and pre-harvest intervals for food crops intended for human or animal consumption. ${ }^{3-5}$

The maximum residue limit (MRL), which is the maximum concentration of pesticide residue allowed in foods of plant origin, is established based on field studies. Such studies provide data about pesticide residues to governments during the registration process to support the establishment of national MRLs, or to the JMPR (Joint FAO/WHO Meeting on Pesticide Residues) for MRL recommendations to the Codex Alimentarius.

In Brazil, the National Health Surveillance Agency (ANVISA) is responsible for the registration of pesticides and for conducting risk assessments of human exposure to these substances and contaminants in foods. ${ }^{6}$ However, the biggest problem is the daily intake of contaminated food and that cannot yet be assessed. Simultaneous exposure to multiple chemicals in the diet (cumulative) and/or originating from multiple sources of exposure (aggregate), and its consequences for human health is a major concern for regulators and the general population. The toxic effects of two or more substances in

*e-mail: srissato@fc.unesp.br the body can be independent, additive or interactive (e.g., synergism, potentiation or antagonism). ${ }^{7}$

The lack of national leadership to protect water resources from nonpoint source pollution from agriculture, combined with the additional threats posed by pesticides to the environment and public health, constitute a strong argument for finding more viable, effective and safe alternatives. ${ }^{8,9}$ In this context, numerous studies have examined the effects of botanical insecticides and semi-processed compounds of vegetal origin on a variety of weeds, and have found them to be biodegradable and less toxic alternatives for use at different scales of agricultural production. The aforementioned studies also investigated the insecticidal properties, including the repellent and regulatory action on insect populations, of different aromatic plant extracts such as macerated extract, organic extract or essential oils, using the whole plant or a fraction of it. ${ }^{10}$ Monoterpenes, the main components of aromatic plants, are generally of special industrial interest due to their biological activity which is applicable in the pharmaceutical and cosmetics industries, in addition to their insecticidal properties. ${ }^{11}$

In this context, among the important compounds derived from Euphorbiaceae species is that of the castor oil plant (Ricinus communis), a drought-resistant tropical plant that thrives in hot and sunny climates. This plant can be considered a low-cost source of castor oil in world markets. The castor bean is completely usable; its main product is oil, which retains its stability in a wide range of temperatures and pressures, while its by-product - castor bean cake - can be used as an organic fertilizer. ${ }^{12}$

Soaps were the first compounds used for insect control, and although they were later replaced by synthetic organic compounds, today's environmental preservation concerns have driven research to focus on less toxic or biocompatible materials. ${ }^{10}$

Castor oil derivatives and soap have similar properties, since they contain lipophilic acyl chains and free hydroxyl groups. Alkaline and free fatty acids result from the partial hydrolysis of soap when mixed with water. ${ }^{12}$ Fatty acids are known to be insecticidal and their activity is maximized through saponification and esterification. ${ }^{13,14}$ Although 
it is believed that fatty acid soaps may disrupt the cell membrane integrity of insects, ${ }^{15,16}$ suffocation is considered the probable mechanism due to the high wettability of soap and to other surfactant solutions; otherwise, those free fatty acids esters would solubilize and disrupt the sugars in the cell membrane. ${ }^{17}$

Given the importance of human and environmental safety, such a mechanism may be of particular interest today. Another relevant quality of castor oil derivatives is their non-phytotoxicity to many plant species at concentrations that are effective against mites and aphids, which can be very important when using insecticidal soaps.

In an endodontic study, ${ }^{18}$ the detergent showed antibacterial activity comparable to that of $0.5 \%$ sodium hypochlorite, with a decrease of facultative microorganisms, when used for irrigation in the chemical-mechanical preparation of teeth with necrotic pulp and periapical lesions. Currently, a product containing this substance is commercially available in Brazil. ${ }^{19}$

This paper reports the results of an investigation of the effect of an ester obtained from the castor oil plant (Ricinus communis) on greenhouse strawberries allied to other pesticides that are commonly found in strawberry crops.

\section{EXPERIMENTAL}

\section{Reagents, solvents and reference pesticide standards}

Acetone, dichloromethane, ethyl acetate and $n$-hexane, all of special grade for pesticide residue analysis, were purchased from J. T. Baker, Mallinckrodt Baker Inc. (Phillipsburg, NJ). Acetonitrile and cyclohexane were of HPLC grade and were obtained from Fisher Scientific Ltd. (USA). Triethylamine, sodium chloride, sodium sulfate and stannous chloride were of analytical reagent grade and were supplied by Merck. Trifluoroacetic anhydride, carbon disulphide and 1-methyl-imidazole were obtained from Sigma (Buchs, Switzerland),

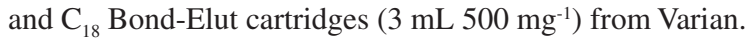

The purified water was obtained from a MilliQ water system (Millipore, Bedford, MA, USA). Pesticide standards were purchased from Dr. Ehrenstorfer (Ausburg, Germany) and most of them were of $>99 \%$ certified purity.

The tests were performed with $10 \%$ castor oil-based detergent from Endoquil, Poliquil Polímeros Químicos Ltda, SP, Brazil.

All the glassware was silanized with a solution of dimethyldichlorosilane 5\% (v/v) prepared in toluene.

\section{Samples}

The present study was designed to focus mainly on the behavior of a list of pesticides usually applied on open field-cultivated strawberries and on dosages recommended by Brazil's National Health Surveillance Agency (ANVISA). ${ }^{20}$

Castor oil-based detergent was applied to the samples of this study in an aqueous solution of $1.5 \mathrm{~mL} \mathrm{~L}^{-1}$. This concentration was chosen based on the results obtained in previous experiments of dosage adjustment experiments to determine the best balance for plant growth from a general agronomic standpoint.

The experiments were carried out in a properly disinfected greenhouse. Strawberry matrix plants of Dover cultivars were planted in 66 polystyrene pots containing autoclaved substrate, using vegetable garden soil and manure in a proportion of 2:1.

During the experiment, the pots were divided into two groups, which were exposed to controlled conditions: temperature of $25^{\circ} \mathrm{C}$, humidity of $60 \%$ and luminosity of $10 \mathrm{~h} \mathrm{day}^{-1}$. Two weeks after planting, the two groups received specific treatment with the respective product dosages (Table 1).
The samples in each group were initially sprayed by foliar microaspersion with the pesticides abamectin, deltamethrin, folpet, mancozeb and tebuconazole. After three days, neutral castor oil soap (Tween 80 ) and distilled water were sprayed on the samples, as indicated in Table 2 . These procedures were repeated at 7-day intervals until the plants began to form flower buds.

The fruits were harvested upon ripe, following a methodology described in the literature. ${ }^{21}$ All the fruits were weighed and their shape and texture evaluated, after which they were frozen at $-30{ }^{\circ} \mathrm{C}$ until the moment of extraction.

\section{Extraction procedures and instrument operating conditions}

Since pesticides belong to different chemical classes and thus have distinct physical properties, the determination of these compounds involved different steps, such as extraction, cleanup and analysis.

In the first method, deltamethrin, folpet and tebuconazole were determined together and the volatility of these compounds allowed for an analysis by gas chromatography-mass spectrometry. Moreover, the method provided adequate limits of recovery and quantification for the goals of this work.

The second method, liquid chromatography was used in the analysis because of the thermal stability and high-molecular-weight class of avermectin. In spite of good separation, a fluorescence derivatization reaction was introduced in the analytical method to increase its sensitivity and enhance the limits of detection and quantification.

The validated methods employed to analyze strawberry samples were:

\section{Method 1}

The pesticides folpet, deltamethrin and tebuconazole were determined using a multiresidue method which is described in the literature..$^{22,23}$

A $50 \mathrm{~g}$ portion of the homogenate strawberry sample was extracted with $80 \mathrm{~mL}$ of acetone in an ultrasonic bath for $20 \mathrm{~min}$ and then vacuum-filtered through a Buchner funnel. A volume of $25 \mathrm{~mL}$ of saturated $\mathrm{NaCl}$ solution and $250 \mathrm{~mL}$ of distilled water were added to the filtrate, followed by liquid-liquid partitioning with $2 \times 50 \mathrm{~mL}$ of dichloromethane. The organic phases were combined, dehydrated by passing them through a filter containing a bed of anhydrous $\mathrm{Na}_{2} \mathrm{SO}_{4}$, and concentrated using a rotary vacuum evaporator equipped with a $40{ }^{\circ} \mathrm{C}$ water bath. The sample was then dried under a gentle stream of pure nitrogen. The residue was dissolved in $3 \mathrm{~mL}$ of ethyl acetatecyclohexane mixture $(1: 1, \mathrm{v} / \mathrm{v})$ and $0.5 \mathrm{~mL}$ of sample was injected into the GPC System using a Shodex GPC K 800 column $(300$ x $8.0 \mathrm{~mm}$, at $100 \AA$ ), and the same solvent mixture as mobile phase operating at a flow rate of $1 \mathrm{~mL} \mathrm{~min}^{-1}$. The fraction eluted between 11 and $13 \mathrm{~min}$ was then collected and evaporated to dryness under a gentle flow of high purity nitrogen at $40^{\circ} \mathrm{C}$ maximum temperature. The final volume was then adjusted to $1 \mathrm{~mL}$ with the acetone- $n$-hexane mixture $(1: 1$, $\mathrm{v} / \mathrm{v})$ prior to the GC analysis.

Sample analysis was specially developed using a Agilent Technologies Model 5890 Series II gas chromatographer with a HP 5972 mass spectrometer (quadrupole) and a fused-silica capillary column with 5\% phenyl-95\% methylpolysiloxane (30 m x $0.25 \mathrm{~mm}$ I.D, $0.25 \mu \mathrm{m}$ film thickness). The gas chromatographer was operated under the following conditions: initial temperature of $130{ }^{\circ} \mathrm{C}$, increments of $8{ }^{\circ} \mathrm{C} / \mathrm{min}$ up to $280^{\circ} \mathrm{C}$, holding for $1 \mathrm{~min}$ (total run time: $20.35 \mathrm{~min}$ ); injection port temperature $250{ }^{\circ} \mathrm{C}$; carrier gas $\mathrm{He}$, operating in the splitless mode; purge off time $45 \mathrm{~s}$; injection size $2 \mu \mathrm{L}$. The operating parameters of the mass spectrometer were: electron ionization at $70 \mathrm{eV}$, ion source temperature $230{ }^{\circ} \mathrm{C}$, transfer line $280^{\circ} \mathrm{C}$, electron multiplier voltage $1200 \mathrm{~V}$, solvent delay $2.9 \mathrm{~min}$; electron scan rate $1.5 \mathrm{scans} / \mathrm{s}$. 
Table 1. Details of the pesticides and products used

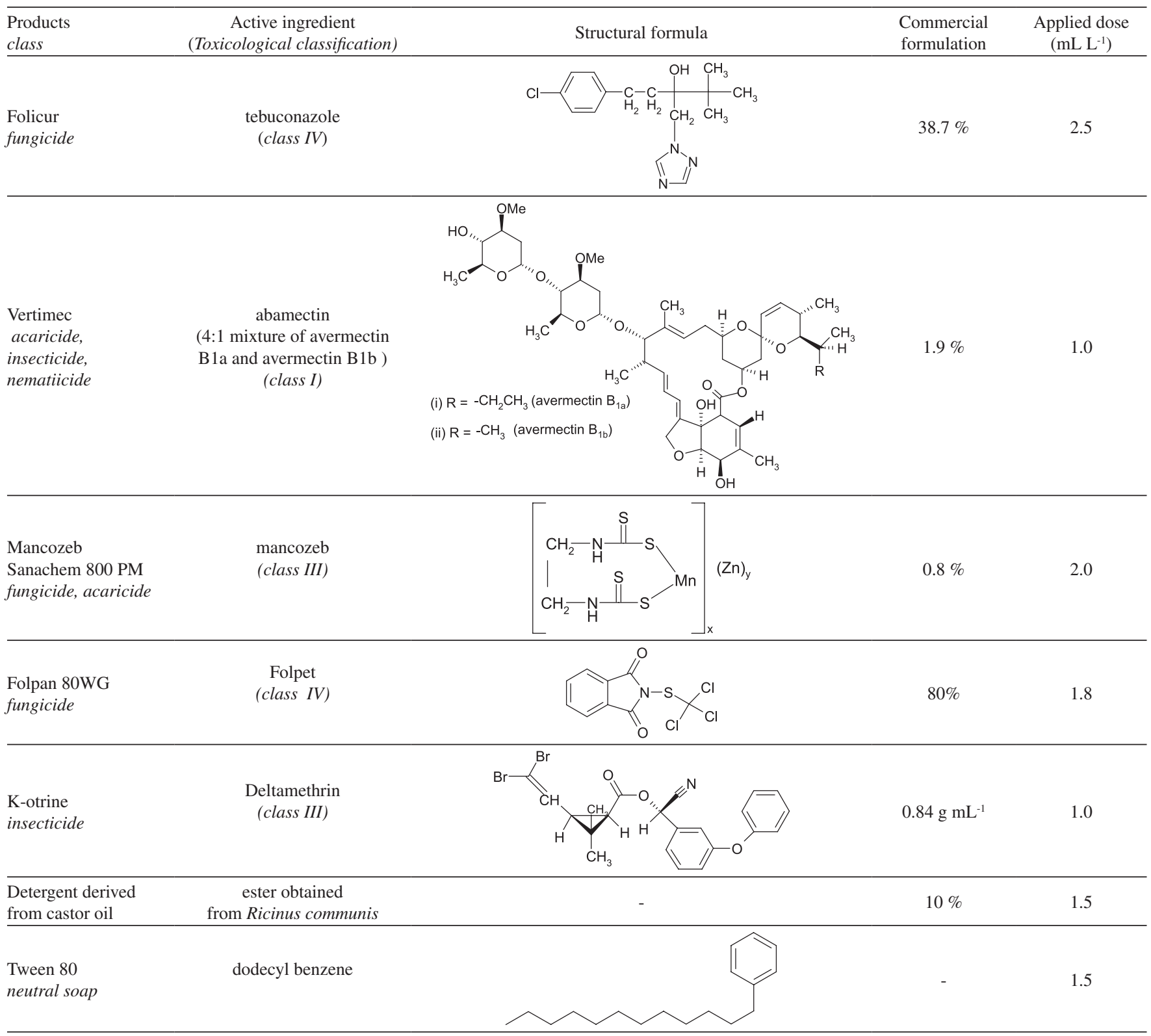

Table 2. Treatments used in strawberry crops studies

\begin{tabular}{|c|c|c|c|c|}
\hline Group 1 & Group 2 & Group 3 & Group 4 & Group 5 \\
\hline tebuconazole & tebuconazole & tebuconazole & tebuconazole & water \\
\hline abamectin & abamectin & abamectin & abamectin & \\
\hline folpet & folpet & folpet & folpet & \\
\hline mancozeb & mancozeb & mancozeb & mancozeb & \\
\hline \multirow[t]{2}{*}{ deltamethrin } & deltamethrin & deltamethrin & deltamethrin & \\
\hline & $\begin{array}{l}\text { detergent derived } \\
\text { from castor oil }\end{array}$ & neutral soap & water & \\
\hline
\end{tabular}

The quantitation was based on calibration with standard pesticides, using the mass spectrometric parameters [selective ion monitoring (SIM) mode] for the molecular ion of each analyte: $\mathrm{m} / \mathrm{z} 262+260$ for folpet, $\mathrm{m} / \mathrm{z} 253$ for deltamethrin and $\mathrm{m} / \mathrm{z}, 250$ for tebuconazole (Figure 1).

The recovery study was carried out by spiking blank control samples of strawberry at two levels of fortification $(0.01$ and $0.10 \mathrm{mg}$ $\mathrm{kg}^{-1}$ ) in triplicate with an adequate volume of folpet, deltamethrin or tebuconazole solution. The fortified samples were subjected to the above described extraction and cleanup steps.

A $25 \mathrm{mg}$ of each reference standard was dissolved in $500 \mathrm{~mL}$ of acetone to yield a stock solution of $50 \mu \mathrm{g} \mathrm{mL}^{-1}$. The stock solutions were diluted, and the standard solutions of each pesticide (stored in glass-stoppered flasks at $-20{ }^{\circ} \mathrm{C}$ ) were used to create a calibration 


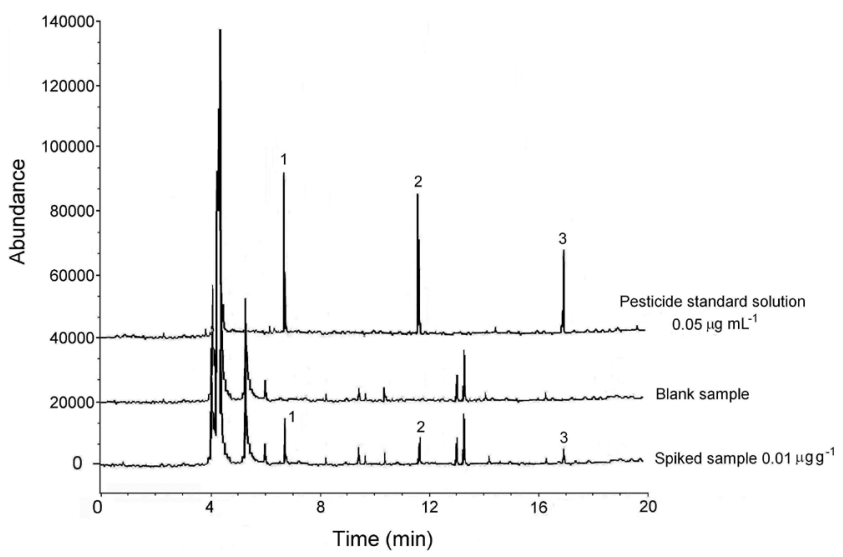

Figure 1. GC-MS (SIM) chromatograms of the pesticides standard solution, blank strawberry sample and spiked strawberry sample obtained from method 1. Peaks: $1=$ folpet, $2=$ tebuconazole, $3=$ deltamethrin

curve ranging from 0.05 to $25 \mu \mathrm{g} \mathrm{mL}^{-1}$. The solutions were injected in quadruplicate and a calibration curve was built by plotting the average peak area counts against folpet, deltamethrin or tebuconazole concentration in $\mu \mathrm{g} \mathrm{mL} \mathrm{m}^{-1}$.

\section{Method 2}

The analytical method used in this study was based on the literatu$\mathrm{re}^{24,25}$ with a few modifications or adaptations for the local laboratory and sample conditions.

Five $g$ of ground sample were homogenized and extracted in an ultra-turrax with a $3 \times 15 \mathrm{~mL}$ of acetonitrile for $45 \mathrm{~s}$. Each extract portion was then transferred to a tube and centrifuged for $1 \mathrm{~min}$ at 3000 $\mathrm{rpm}$. The supernatant liquid phase was combined and quantitatively transferred to a $50 \mathrm{~mL}$ volumetric flask, whose volume was completed with triethylamine $1 \%$ in distilled water. This solution was percolated at a flow rate of $1 \mathrm{~mL} \mathrm{~min}^{-1}$ through a $\mathrm{C}_{18} \mathrm{SPE}$ cartridge preconditioned with $5 \mathrm{~mL}$ of acetonitrile/water 80:20 (v/v). The analyte abamectin was finally eluted with $7 \mathrm{~mL}$ of acetonitrile, evaporated to dryness under a stream of high purity nitrogen quantitatively dissolved in $1 \mathrm{~mL}$ of acetonitrile. A derivatization solution of $500 \mu \mathrm{L}$ of acetonitrile/trifluoroacetic anhydride 2:1 (v/v) and $200 \mu \mathrm{L}$ of $\mathrm{N}$-methyl-imidazole was added, vigorously shaken, and stored at room temperature for $30 \mathrm{~min}$. An aliquot of this sample was then injected into a high performance liquid chromatography system (HPLC), Figure 2.

The HPLC system consisted of an analytical Brownlee C-18 column $(100 \times 4.6 \mathrm{~mm} \times 3.0 \mu \mathrm{m})$, a Jasco PU-980 HPLC pump (Jasco Corp., Tokyo, Japan) running in isocratic conditions with the mobile phase of acetonitrile/water (90:10, v/v), a Rheodyne model 7125 sample injector (Perkin Elmer, Inc., Waltham, MA, U.S.A.), and a $50 \mu \mathrm{L}$ sample loop. The fluorescence detector was a Jasco FP-920 (Jasco Corp.) operating at an excitation wavelength of $365 \mathrm{~nm}$ and emission of $470 \mathrm{~nm}$.

The recovery study was carried out by spiking blank control samples of strawberry at two levels of fortification $(0.01$ and 0.10 $\mathrm{mg} \mathrm{kg}^{-1}$ ) with a suitable volume of abamectin solution. The fortified samples were subjected to extraction and derivatization steps as described above.

The standard stock solution of abamectin was prepared in acetonitrile at $0.05 \mathrm{mg} \mathrm{mL}^{-1}$. Adequate amounts of anhydrous acetonitrile were used to obtain the standard working solutions of 0.01 to $3 \mu \mathrm{g}$ $\mathrm{mL}^{-1}$, which were stored at $-20{ }^{\circ} \mathrm{C}$. The standard solutions were poured into $5 \mathrm{~mL}$ amber micro-reaction vials and evaporated to dryness under a stream of nitrogen, using a heating block at $50{ }^{\circ} \mathrm{C}$. The derivatization was performed as described for the samples. Aliquots

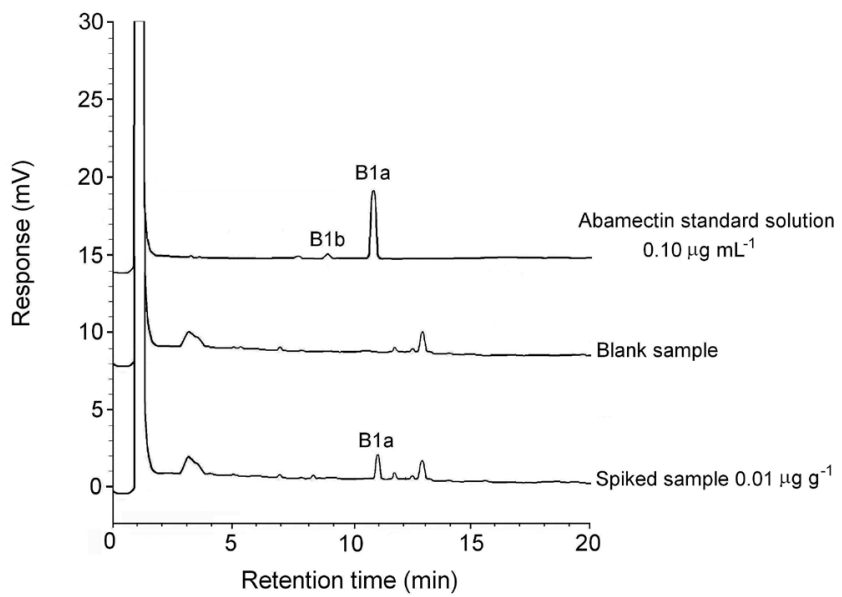

Figure 2. HPLC-fluorescence chromatograms of the abamectin standard solution, blank strawberry sample and spiked strawberry sample obtained from method 2

were injected in triplicate and a calibration curve was constructed by plotting the average peak area counts against the abamectin concentration in $\mu \mathrm{g} \mathrm{mL} \mathrm{L}^{-1}$.

\section{Method 3}

Mancozeb was determined according to the method described in the literature. ${ }^{26,27}$ Mancozeb residues were analyzed as carbon disulfide $\left(\mathrm{CS}_{2}\right)$ by gas-liquid chromatographic headspace.

Fifteen $g$ of ground and sifted sample were transferred into an extraction flask. An aliquot of $40 \mathrm{~mL}$ of a freshly prepared hydrolysis solution $(1.5 \%$ stannous (II) chloride in $5 \mathrm{M} \mathrm{HCl})$ was added to the flask, which was immediately sealed and crimped. Using a $100 \mu \mathrm{L}$ Hamilton syringe, $50 \mu \mathrm{L}$ of $1 \mathrm{mg} \mathrm{mL}^{-1}$ thiophene solution was added to the solution, vigorously shaken, and placed in a laboratory oven at $75^{\circ} \mathrm{C}$, where it was held for $1 \mathrm{~h}$. (Figure 3).

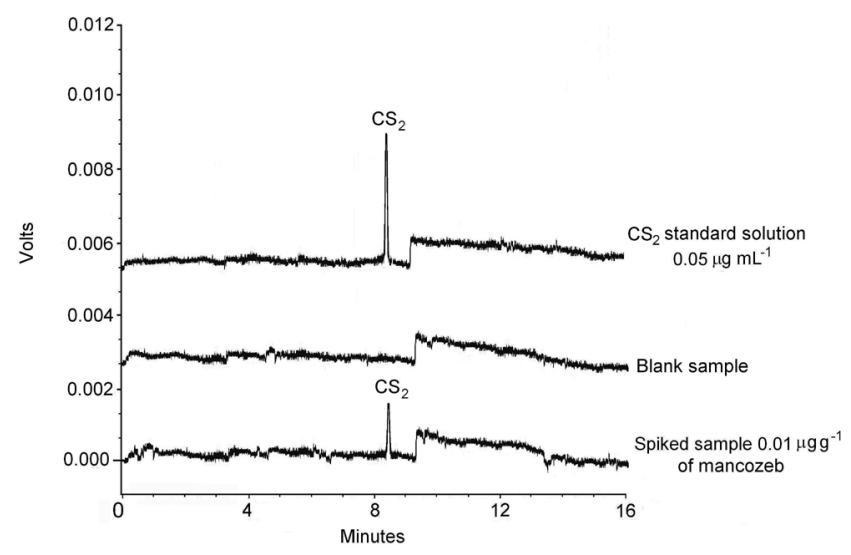

Figure 3. GC-FPD chromatograms of the $\mathrm{CS}_{2}$ standard solution, blank strawberry sample and spiked strawberry sample obtained from method 3

Eighty $\mu \mathrm{L}$ of the evolved $\mathrm{CS}_{2}$ trapped in the headspace vial was injected directly onto the Agilent Technologies Model 5890 Series II gas chromatographer using a gastight syringe, and was detected with a flame photometric detector (FPD) operating in sulfur mode, under the following conditions:

Hydrogen was used as carrier gas at a linear velocity of $42 \mathrm{~cm} \mathrm{~s}^{-1}$ and nitrogen 9.5 analytical degree as make-up gas for the FPD at a flow rate of $25 \mathrm{~mL} \mathrm{~min}^{-1}$. The airflow was set at $105 \mathrm{~mL} \mathrm{~min}^{-1}$ and hydrogen at $73 \mathrm{~mL} \mathrm{~min}^{-1}$. The injection port was set at $200{ }^{\circ} \mathrm{C}$ and 


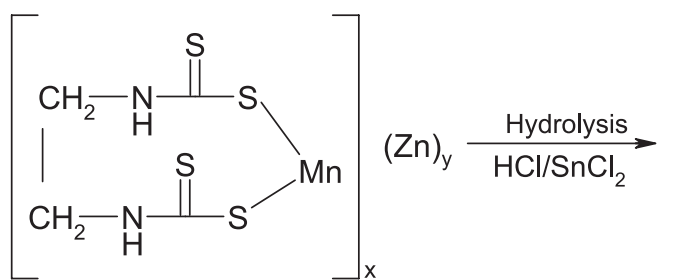

the detector at $250{ }^{\circ} \mathrm{C}$. The analytical column was $5 \%$ phenyl-95\% dimethylpolysiloxane with $25 \mathrm{~m}$ x $0.25 \mathrm{~mm}$ x $5.0 \mu \mathrm{m}$ film thickness. The initial oven temperature was set at $40^{\circ} \mathrm{C}$, held for $1 \mathrm{~min}$, followed by heating at $10^{\circ} \mathrm{C} \mathrm{min}{ }^{-1}$ to a final temperature of $180{ }^{\circ} \mathrm{C}$, where it was held for $1 \mathrm{~min}$.

The mancozeb stock and calibration solutions were prepared in a diluent of $0.2 \mathrm{M}$ ethylenediaminetetraacetic acid and $0.4 \mathrm{M} \mathrm{NaOH}$. The stock solution of $20 \mu \mathrm{g} \mathrm{mL} \mathrm{m}^{-1}$ was prepared and diluted to produce calibration standards of 0.5 to $10 \mu \mathrm{g} \mathrm{mL}^{-1}$. These solutions were used in the recovery study by spiking blank control samples of strawberry at two levels of fortification $\left(0.01\right.$ and $\left.0.10 \mu \mathrm{g} \mathrm{g}^{-1}\right)$ with an adequate volume of mancozeb solution. After spiking, the fortified samples were subjected to the above described extraction step.

The $\mathrm{CS}_{2}$ stock solution of $1 \mathrm{mg} \mathrm{mL}^{-1}$ was prepared in isooctane and diluted with isooctane to produce a calibration curve of 0.01 to $4 \mu \mathrm{g} \mathrm{mL} \mathrm{L}^{-1}$. The aliquots were stored at $-18{ }^{\circ} \mathrm{C}$ and injected in quadruplicate to obtain a calibration curve plotting the average peak area counts against the mancozeb concentration in $\mu \mathrm{g} \mathrm{mL} \mathrm{m}^{-1}$.

All the results are expressed as $\mu \mathrm{g}$ of $\mathrm{CS}_{2}$ per gram of fruit. The conversion factor to mancozeb residues was 1.776 (according reaction 1).

\section{Linearity, recovery, limits and selectivity}

Linear dynamic range, precision, recovery, lower limits and selectivity were evaluated for the analytical method developed here. For the linear dynamic range, the calibration samples were prepared by diluting the stock solution in blank matrix extract to avoid matrix effects.

Lower limits of detection (LOD) and of quantitation (LOQ) were determined as the lowest pesticide concentration injected that yielded signal-to-noise $(\mathrm{S} / \mathrm{N})$ ratios of 3 and 10 , respectively, when the quantitation ion was monitored. ${ }^{28}$ The presence of potential interferences in the chromatograms of the analyzed samples was monitored by running blank control samples in each calibration. The absence of any chromatographic components at the same retention times as the target pesticide suggested that no chemical interference occurred.

\section{Calculation of pesticide residue concentration}

The concentrations of pesticide residues in strawberry samples were calculated based on the area of the integrated peaks of the samples compared with known concentrations of analytical standard of the pesticides under study, considering the dilution volume and mass of the sample. The residue was given by the amount of pesticide present in the injected volume (obtained from the calibration curve), which was then multiplied by the final dilution volume to indicate the mass of analyte present in this step.

To determine the residue in parts per million, the mass present in the dilution volume $(\mu \mathrm{g})$ was then divided by the initial mass of the strawberry sample $(\mathrm{g})$. This residue should then be adjusted, depending on the average recovery rate for each method (Equation 1):

$$
R_{(\mu g / g)}=\frac{C \times V_{f} \times 100}{m \times R}
$$

$C=$ analytical concentration (obtained from the calibration curve); $V_{f}$ = final dilution volume; $m=$ sample mass; $R=$ recovery.

\section{RESULTS AND DISCUSSION}

\section{Validation studies}

All the analytical conditions were developed especially or adapted for the matrix under study, mainly to avoid co-elution and to optimize the analysis time, solvent and sorbent consumption in an appropriate resolution balance.

Validation studies were performed with blank samples or certified pesticide-free strawberry. The linearity of the response limits was studied using matrix-matched calibration solutions. The resulting determination coefficients were higher than 0.994 in each case. The limits of detection (LOD) ranged from $0.001 \mathrm{mg} \mathrm{kg}^{-1}$ for abamectin to $0.05 \mathrm{mg} \mathrm{kg}^{-1}$ for deltamethrin, allowing for the applicable quantification of the selected pesticides (Table 3 ).

Repeatability was evaluated by spiking two blank samples with concentrations of 0.01 and $0.10 \mathrm{mg} \mathrm{kg}^{-1}$ of all the studied pesticides. The results, expressed as relative standard deviation (RSD), ranged from 3 to $9 \%$. The inter-day reproducibility $(n=3)$ was also evaluated at the same concentration as that used for the repeatability analysis. The results varied from 5 to $11 \%$.

The limits of quantification (LOQ) of the method were calculated as the lowest concentration at which the RSD was less than 5\%. Taking into account the preparation of samples, the LOQ of the pesticides in the strawberry matrix ranged from 0.005 to $0.01 \mathrm{mg} \mathrm{kg}^{-1}$ (Table 3).

Table 3. Validation parameters of the analytical methodologies

\begin{tabular}{|c|c|c|c|c|c|}
\hline \multirow{2}{*}{ Pesticide } & \multirow{2}{*}{$\mathrm{LOD}^{\mathrm{a}}\left(\mu \mathrm{g} \mathrm{g}^{-1}\right)$} & \multirow{2}{*}{$\mathrm{LOQ}^{\mathrm{b}} \quad\left(\mu \mathrm{g} \mathrm{g}^{-1}\right)$} & \multicolumn{2}{|c|}{ Recovery $^{\mathrm{c}}(\%) \pm \mathrm{RSD}$} & \multirow{2}{*}{ Determination coefficient $\left(R^{2}\right)$} \\
\hline & & & $0.01\left(\mu \mathrm{g} \mathrm{g}^{-1}\right)$ & $0.10\left(\mu \mathrm{g} \mathrm{g}^{-1}\right)$ & \\
\hline Tebuconazole & 0.005 & 0.01 & $87 \pm 6$ & $98 \pm 4$ & 0.998 \\
\hline Abamectin & 0.001 & 0.01 & $83 \pm 8$ & $89 \pm 6$ & 0.997 \\
\hline Folpet & 0.005 & 0.01 & $88 \pm 8$ & $85 \pm 6$ & 0.996 \\
\hline Mancozeb $\left(\mathrm{CS}_{2}\right)$ & 0.004 & 0.01 & $82 \pm 7$ & $87 \pm 9$ & 0.998 \\
\hline Deltamethrin & 0.010 & 0.01 & $90 \pm 7$ & $91 \pm 7$ & 0.999 \\
\hline
\end{tabular}

a LOD: limit of detection - analyte concentration producing a $\mathrm{S} / \mathrm{N}=3 .{ }^{\mathrm{b}} \mathrm{LOQ}$ : limit of quantitation. ${ }^{\mathrm{c}}$ Recovery: calculated from six strawberry samples spiked with working standard solution. 
Recovery assays were done in triplicate by spiking homogenized samples of strawberries. The mean recovery rates obtained with spiked samples at the level studied here ranged from $85 \%$ to $98 \%$, with a relative standard deviation (RSD) of less than $10 \%$.

\section{Quality control}

Based on each of the three methods, recovery studies were performed by analyzing a blank strawberry spiked with the appropriate volume of mixed standard pesticide solution at $0.01 \mathrm{mg} \mathrm{L}^{-1}$. Acceptable spike recoveries ranged from 60 to $110 \%$ and the positive results in the strawberry samples were confirmed by comparing the retention time in relation to the standard solution. Retention times fell within $0.08 \mathrm{~min}$ of the expected retention times. The strawberry blank and spikes were analyzed to evaluate any residual interference or possible sources of contamination such as glassware, handling and others. Duplicate samples, along with the regular samples, were analyzed in the laboratory as an additional quality control measure to ensure the validity of the results. Instrument stability and relative response factor variance were determined by analyzing the standard calibration solutions for each sample batch. The LODs for pesticides were defined by a signal-to-noise ratio exceeding three times the average baseline variation, and were within the range of 0.01-0.05 $\mu \mathrm{g} \mathrm{kg}^{-1}$ (dry weight).

Any deviation of more than $15 \%$ required a new injection or analysis of the entire batch to be rejected or repeated. The quantification of any pesticide present in the strawberry extract was determined as previously described.

\section{Strawberry samples}

The castor oil plant (Ricinus communis) whose oil has a high chemical potential offers a wide variety of polyols and prepolymers from fatty acids. This species contains terpenoids whose insecticidal activity on several ant species such as Ata spp. ${ }^{11,29}$ and Epilachna paenulata $\mathrm{M} .{ }^{21}$ has already been tested and confirmed.

In the overall evaluation of the strawberry samples, no biological infestation was detected in the groups treated with pesticides, except for the presence of leaf-cutter ants that attacked group 3, which was treated with neutral soap. Control group 5, which was not treated with pesticide, showed the presence of fungal diseases such as anthracnose (Colletotrichum gloeosporioides, C. acutatum and C. fragariae), grey mold (Botrytis cinerea); of bacterial origin such as the bacteriosis caused by Xanthomonas fragariae and by several arthropod species such as Capitophorus fragaefolii, Tetranychus urticae and the leafcutter ant Atta sexdens rubropilosa.

The qualitative analysis of the harvested fruits showed that all the groups except the one treated with water (group 5) presented compatible shapes and sizes, and a weight of 9 to $10 \mathrm{~g}$ per fruit. Table 4 lists strawberries' sizes and weights.

Table 4. Average weight and total weight of the strawberry fruits

\begin{tabular}{ccc}
\hline Groups & Average weight $(\mathrm{g})$ & Total weight $(\mathrm{g})$ \\
\hline 1 & 10.3 & 560 \\
2 & 10.4 & 585 \\
3 & 8.5 & 421 \\
4 & 9.2 & 515 \\
5 & 6.5 & 395
\end{tabular}

The similarities in fruit size and individual and total weight in the treated groups confirmed that systemic pesticides such as tebuconazole or contact pesticides such as deltamethrin interrupted the life cycle of the biological organism infesting the strawberry crops. ${ }^{30}$

The qualitative analysis of group 5 revealed the fruits' diminished size and aspect, presenting infestation by the bacterium Xanthomonas fragariae and a significant reduction in the quantity of viable fruits, as well as individual and total weight loss.

\section{Evaluation of pesticides}

When applied to crops, abamectin residues degrade into various products by both oxidative and photochemical action. However, residues of toxicological significance are avermectin $B_{1}$ and the metabolite 8,9-Z-avermectin $\mathrm{B}_{1} \cdot{ }^{31}$ Maximum residue limits (MRLs) are thus expressed as the sum of avermectin $B_{1 a}$, avermectin $B_{1 b}$ and of 8,9-Z-avermectin $\mathrm{B}_{1}$. The metabolite 8,9-Z-avermectin $\mathrm{B}_{1}$ yields the same derivative as that obtained from avermectin $B_{1 a}$ when derivatized with trifluoroacetic anhydride. ${ }^{32}$ Therefore, avermectin $\mathrm{B}_{1 \mathrm{a}}$, the metabolite 8,9-Z-avermectin $\mathrm{B}_{1}$, and avermectin $\mathrm{B}_{1 \mathrm{~b}}$ can be determined using this procedure.

Mancozeb belongs to class of ethylene bis-dithiocarbamate (EBDC) fungicides that constitute a group of compounds which exist as strong complexes with zinc and manganese ions in a polymeric form. The direct analysis of these compounds is difficult, particularly due to their low solubility in water, even in a large range of organic solvents. Due to these limitations, the third method, which was employed to determine mancozeb residue, was an analytical method developed by Keppel, ${ }^{33}$ consisting of acid hydrolysis in the presence of stannous chloride and subsequent $\mathrm{CS}_{2}$ analysis of this reaction using a GC-FPD. ${ }^{26,34}$

The maximum residue limits of mancozeb in food are expressed in milligrams of carbon disulfide equivalents per kilogram of food. 5,6,35

The literature contains several reports about treatments to reduce pesticide residues in fruit samples using methods such as immersion, spraying, using water as solvent, temperature and others. ${ }^{36,37}$ However, water solubility is not a decisive factor that can be correlated consistently with the rinsability of a pesticide in any type of food, because some pesticides may be translocated into the plant's internal tissues in the field, making them inaccessible to any water rinsing procedure. ${ }^{1}$

Plant oils with insecticidal potential represent an important alternative for controlling insect pests in several crops. Hot water extract of castor-oil plant leaves presented insecticidal activity against Callosobruchus chinensis (Coleoptera: Bruchidae). ${ }^{38,39}$ In a field study, Mushobozy et al. found that castor oil can present insecticidal activity against Zabrotes subfasciatus (Coleoptera: Bruchidae). ${ }^{40,41}$

In this work, the performance of castor oil-based detergent was studied in the cultivation of strawberries under diverse conditions.

Table 5 presents the results obtained for pesticide residues in all the experimental groups. Group 5 (control group) presented high infestation by fungi, bacteria and insects, indicating that the absence of these products in greenhouse strawberries becomes unfeasible, affecting their weight and final production. Our results confirm reports in the literature about the difficulties involved in cultivating strawberries in damp and warm environments. ${ }^{30}$

Group 1 showed the highest concentration of pesticide residues,

Table 5. Pesticide residues $\left(\mu \mathrm{g} \mathrm{g}^{-1}\right)$ determined in strawberry samples

\begin{tabular}{lccccc}
\hline \multirow{2}{*}{ Pesticides } & \multicolumn{5}{c}{ Residue $\left(\mathrm{mg} \mathrm{g}^{-1}\right)$} \\
\cline { 2 - 6 } & Group 1 & Group 2 & Group 3 & Group 4 & Group5 \\
\hline abamectin & 0.05 & nd & nd & 0.02 & nd \\
folpet & 4.32 & nd & 0.37 & 1.69 & nd \\
deltamethrin & 0.07 & $<0.01$ & 0.01 & 0.03 & nd \\
mancozeb $\left(\mathrm{CS}_{2}\right)$ & 0.21 & 0.02 & nd & 0.12 & nd \\
tebuconazole & 0.10 & $<0.01$ & 0.05 & 0.10 & nd \\
\hline
\end{tabular}


followed by groups 4 and 3 . The highest pesticide residues found were folpet (1.69 to $4.32 \mu \mathrm{g} \mathrm{g}^{-1}$ ) and mancozeb (0.12 to $\left.0.21 \mu \mathrm{g} \mathrm{g}^{-1}\right)$, which are classified, respectively, as moderately toxic and slightly toxic.

The lowest concentration of pesticides residue was found in group 2 , which was treated with castor oil-based detergent, and whose fruits were also of good quality. The highest amount of pesticide residue found was from mancozeb $\left(0.02 \mu \mathrm{g} \mathrm{g}^{-1}\right)$, which is classified as moderately toxic.

Due to the tensioactive properties of castor oil-based detergent, which are similar to those of regular detergent, the group treated with commercial neutral soap (group 3) was also studied to verify the performance of this tensioactive agent. The castor oil-based detergent presented the best results due to its low saponification and high detergent activity, proving to be more selective than a regular neutral soap. Another relevant difference among the groups is that group 3 was the only one attacked by leaf-cutter ants (Atta sexdens rubropilosa). This likely indicates the inactivation or degradation of the compounds of the plant's secondary metabolism, which are natural herbivore repellents. ${ }^{42}$

The research and use of castor oil-based detergent is still incipient, but the results are highly promising in view of its apparent efficiency in the control of microorganisms, its low toxicity and its low cost in Brazil. For the other hand, it could represent an excellent alternative to control a wide range of organisms, since it is environmentally safe, biodegradable, non-resistible to botanical insecticides, and its cost is low.

\section{CONCLUSIONS}

Oils of plant origin are readily available and can be used in small amounts as adjuvants in tank-mix pesticide formulations. However, edible oils and petrochemical oils may be too expensive to consider for large-scale agricultural use. Castor oil, which is non-edible and abundant in several countries including Brazil, may be very useful in agricultural programs.

Our experimental results indicated that the castor oil-based detergent applied on strawberry crops, in conjunction with well known and established pesticides, can be a useful alternative due to its properties of low phytotoxicity to many plant species and to the fact that its residues break down rapidly through microbial action in the environment, translating into safety for humans and the environment.

\section{REFERENCES}

1. Hamilton, D.; Crossley, S. In Pesticide Residues in Food \& Drink Water; Hamilton, D.; Crossley, S., eds., John Wiley \& Sons Ltd: England, 2004.

2. Veiga, M. M.; Rev. C. S. Col. 2007, 12, 145.

3. FAO/OMS, Codex Alimentarius; Residuos de Plaguicidas em los alimentos, FAO/OMS: Roma, 1994, vol. 2.

4. Olkowski, W. In Common Sense Pest Control; Timmons, C. ed.; Taunton Press: Newtown, 1991.

5. http://www.epa.gov/opp00001/food/viewtols.htm, accessed on April 2011.

6. http://www.anvisa.gov.br, accessed on March 2011.

7. Jardim, A. N. O.; Caldas, E. D.; Quim. Nova 2009, 32, 1898.

8. Tapondjou, A. L.; Adler, C.; Fontem, D. A.; Bouda, H.; Reichmuth, C.; J. Stored Prod. Res. 2005, 41, 91.

9. Galembeck, F.; Barbosa, A. S.; Sousa, R. A.; Quim. Nova 2009, 32, 571.

10. Lee, B. H.; Annis, P. C.; Tumaalii, F.; Choi, W. S.; J. Stored Prod. Res. $\mathbf{2 0 0 5}, 40,553$.

11. Weinzierl, R. A. In Biological and biotechnological control of insect pests; Jack, E. R. ed., Lewis Publishers: Boca Raton, 2000.
12. Costa, H. M.; Polímeros 2007, 14, 46.

13. Isman, M.; Akhtar, Y. In Insecticides Design Using Advanced Technologies; Horowitz, A. R., ed., Springer Berlin Heidelberg: New York, 2007.

14. Collavino, M.; Pelicano, A.; Gimenez, R. A.; Rev. FCA UNCuyo 2006, $38,13$.

15. Kabara, J. J. In Ecology and metabolism of plant lipids; ASC Symp. Ser. Amer. Chem. Soc.; Fuller, L. G., ed., W. D. Ness: Washington, 1987.

16. Silva, M. A. N.; Marques, F. A.; Duque, L. J. E.; Rev. Bras. Entomol. 2009, 53, 1 .

17. Wang, C.; Xing, J.; Chin, C.; Peters, J.; Phys. Mol. Plant Pathol. 2002, $61,151$.

18. Ferreira, C. M.; Bonifácio, K. C.; Fröner, I. C.; Ito, I. Y.; Braz. Dent. J. 1999, 10, 15.

19. Claro, S.; Chierice, G. O.; Reimer, A. J.; Al-Asfour, S. V.; Ribero, O. M.; Meneguelo, R.; De Almeida, M. V.; Br PI 0.800.460-9 A2, 2008.

20. http://www4.anvisa.gov.br/AGROSIA/asp/frm_pesquisa_agrotoxico.asp. accessed on April 2011.

21. Pelicano, A.; Rodríguez, S.; Caffarini, P.; Delfino, S.; Canepa, D.; Rev. de la Assoc. Arg. Hort. 2001, 20, 23.

22. Gelsomino, A.; Petrovicová, B.; Tiburtini, S.; Magnani, E.; Felici, M.; J. Chromatogr., A 1997, 782, 105.

23. Rissato, S. R.; Galhiane, M. S.; Souza, A. G.; Apon, B. M.; J. Braz. Chem. Soc. 2005, 16, 1038.

24. Diserens, H.; Henzelin, M.; J. Chromatogr., A 1999, 833, 13.

25. Kolberg, D. I. S.; Presta, M. A.; Wickert, C.; Adaime, M. B.; Zanella, R.; J. Braz. Chem. Soc. 2009, 20, 1220.

26. Bastos, L. H. P.; Góes, H. C. A.; Cardoso, M. H. W. M.; Gouvêa, A. V.; Dias, D. P.; Almeida, R. R. R.; Nóbrega, A.; Abrantes, S.; Quim. Nova 2007, 30, 32 .

27. Kontou, S.; Tsipi, D.; Tzia, C.; Food Addit. Contam. 2004, 21, 1083.

28. ICH, International Conference on Harmonization; ICH Q2(R1), Guidance on Validation of Analytical Procedures: Text and Methodology, ICH: Geneva, 2005.

29. Acacio-Bigi, M. J. A.; Hebling, O. C.; Bueno, F. C. M.; Rev. Bras. Ent. 1998, 41, 239.

30. Fadini; M.; Pallini, A.; Venzon, M.; Ciência Rural 2004, 34, 1271.

31. Pesticide Residues in Food Products, Report 1992, Joint Report FAO/ OMS, p. 116.

32. Kolberg, D. I. S.; Presta, M. A.; Wickert, C.; Adaime, M. B.; Zanella, R.; J. Braz. Chem. Soc. 2009, 20, 1220.

33. Keppel, G. E.; J. AOAC 1971, 54, 528.

34. Papadopoulou-Mourkidou, E.; Papadakis, E. N.; Vryzas, Z. In Pesticide Protocols; Vidal, J. L. M.; Frenich, A. G., eds., Humana Press Inc.: Totowa, 2006.

35. Official Journal of the European Union; Commission Directive 2007/57/ EC of 17 September 2007 - amending certain Annexes to Council Directives 76/895/EEC, 86/362/EEC, 86/363/EEC and 90/642/EEC as regards maximum residue levels for dithiocarbamates.

36. Keikotlhaile, B. M.; Spanoghe, P.; Steurbaut, W.; Food Chem. Toxicol. 2010, 48, 1.

37. Guardia-Rubio, M.; Ayora-Cañada, M. J.; Ruiz-Medina, A.; J. Food Sci. 2007, 72, 139.

38. Dorner, J. W.; J. Food Prot. 2010, 73, 495.

39. Caffarini, P.; Carrizo, P.; Pelicano, A.; Roggero, P.; Pacheco, J.; Idesia 2008, 26, 59.

40. Lyn, M. E.; Burnett, D.; Garcia, A. R.; Gray, R.; J. Agric. Food Chem. 2010, 58, 1804 .

41. Mushobozy, D. M. K.; Nganilevanu, G.; Ruheza, S.; Swella, G. B.; J. Plant Prot. Res. 2009, 49, 35.

42. Taiz, L.; Zeiger, E.; Plant Physiology, $5^{\text {th }}$ ed., Sinauer Associates: Sunderland, 2006. 